Wilfrid Laurier University

Scholars Commons @ Laurier

1999

\title{
Nest-Site Selection by Female Black-Capped Chickadees: Settlement Based on Conspecific Attraction?
}

\author{
Scott M. Ramsay \\ Ken A. Otter \\ Queen's University -- Kingston \\ Laurene M. Ratcliffe \\ Queen's University - Kingston
}

Wilfrid Laurier University, sramsay@wlu.ca

Follow this and additional works at: https://scholars.wlu.ca/biol_faculty

\section{Recommended Citation}

Ramsay, Scott M.; Otter, Ken A.; and Ratcliffe, Laurene M., "Nest-Site Selection by Female Black-Capped Chickadees: Settlement Based on Conspecific Attraction?" (1999). Biology Faculty Publications. 35. https://scholars.wlu.ca/biol_faculty/35 


\title{
NEST-SITE SELECTION BY FEMALE BLACK-CAPPED CHICKADEES: SETTLEMENT BASED ON CONSPECIFIC ATTRACTION?
}

\author{
SCOTt M. Ramsay, ${ }^{1}$ Ken OtTer, ${ }^{2}$ AND Laurene M. RatClifFe \\ Department of Biology, Queen's University, Kingston, Ontario K7L 3N6, Canada
}

\begin{abstract}
Female Black-capped Chickadees (Poecile atricapillus) solicit extrapair copulations (EPCs) from neighboring high-ranked males, and these EPCs result in extrapair young. Females might choose to locate their nests near the territory boundaries of attractive males to facilitate access to EPCs. Other hypotheses might also explain choice of nest site, namely: (1) habitat characteristics, (2) prey abundance, and (3)previous experience. We tested these four hypotheses in 1996 and 1997. Out of 27 habitat characteristics measured, we found only one that was significantly different between nests and control sites in both years. The abundance of large trees was lower at nest sites than at control sites in each year and when years were pooled. Relative prey abundance did not differ between nests and control sites for either year of the study. We found no difference in interyear nest placement based on female experience, experienced females nested farther than $60 \mathrm{~m}$ from their previous nest sites in both years of the study. In 1996, females whose neighboring males were higher ranked than their social partner located their nests significantly closer to territory boundaries than did females whose nearest neighbors were lower ranked than their social partner. In 1997, all pairs nested near territory boundaries. We conclude that choice of nest location in Black-capped Chickadees is influenced by conspecific attraction based on mating tactics. Received 26 December 1997, accepted 6 November 1998.
\end{abstract}

Habitat Quality traditionally has been viewed as the primary factor in nest-site selection for birds (Danchin and Wagner 1997).Prey abundance may influence choice of nest sites through the benefits of more efficient nestling provisioning (Schroeder 1990, Smith 1991). At the microsite scale, predation risk may be related to characteristics of the nest site, but studies considering this factor have shown little evidence that birds avoid sites that are vulnerable to predation (e.g. Albano 1992, Christman and Dhondt 1997).Previous experience also may influence where individuals choose to nest (Beletsky and Orians 1991, Muller et al. 1997). Recent interest has focused on how conspecificattraction influences settlement patterns (see Stamps 1988,Danchin and Wagner 1997).Here, we cxaminc the contributions of habitat char acteristics, prey abundance, previous experience, and conspecific attraction toward choice of nest location in Black-capped Chickadees (Poecile atricapillus).

Black-capped Chickadees are nonmigratory songbirds that excavate nest cavities. With but

\footnotetext{
${ }^{1}$ E-mail: ramsays@biology.queensu.ca

${ }^{2}$ Present address: Zoological Institute, University of Copenhagen, Tagensvej 16, DK-2200, Copenhagen $\mathrm{N}$, Denmark
}

few exceptions, the female is responsible for choice of nest location (Odum 1941, Smith 1974). Both members of the pair participate in excavation (Smith 1991), but measured as the proportion and duration of excavation visits, the female expends more effort than the male (S. Ramsay unpubl. data), and the female alone builds the actual nest (Smith 1991).

Studies of nest-site selection in chickadees have yielded inconsistent results. Some studies have suggested that high canopy volume is associated with nest sites (Smith 19/6; but see Sedgwick and Knopf 1990), which may be related to prey abundance (Schroeder 1990). A study in Colorado found that, unlike for other species of cavity nesters, no single variable or pair of variables could be used to discriminate chickadee nest sites from control sites (Sedgwick and Knopf 1990). Sedgwick and Knopf (1990) also found that variables related to the amount of wood suitable for excavation were positively associated with chickadee nest sites (e.g. limb-tree density, density of large trees, and length of dead limbs on focal trees).

Prey abundance, as a specific habitat characteristic, may be a factor that influences choice of nest location, and this may be related to other variables as outlined above (Schroeder 1990). By locating a nest in a patch of high food den- 
sity, an individual would reduce the time spent traveling between nest sites and foraging sites during the critical period of nestling provisioning (Horn 1968, Orians and Pearson 1979). Smith (1976) suggested that smaller territory size and increased canopy density would increase the number of provisioning trips adults can make by reducing search and travel times. Therefore, if an individual can predict the location of dense patches of arthropods, it may be influenced to excavate a nest cavity in that location.

The previous-experience hypothesis suggests that choice ul current nest location is related to nest location in the year before; the pattern of settlement for new residents would be random comparcd with locations chosen by previous residents. Specifically, the two predictions that derive from this hypothesis are (1) females that nest on the same territory in multiple years will nest closer to previous nest sites than will new residents, and (2) females that nested successfully in the previous year will nest nearer to the old nest site than those that nested unsuccessfully the previous year.

The conspecific-attraction hypothesis suggests that individuals choose nest locations based on the presence of other individuals. Individuals may be attracted to conspecifics for a variety of reasons (Stamps 1988). Younger individuals may be attracted to older individuals to reduce effort in habitat assessment (Stamps 1988, Muller et al. 1997). This factor might be especially important in migratory species where the time between arrival and settlement on the breeding ground is relatively short. Another reason individuals might be attracted to conspecifics is the ability to obtain multiple matings in aggregations (Lack 1948, Birkhead 1978).

Recent studies have demonstrated that mixed mating tactics are common iri many bird species (Smith 1988, Houtman 1992, Kempenaers et al. 1992, Lifjeld and Robertson 1992, Wagner et al 1996, Neudorf et al. 1997). Prior to genetic evidence of extrapair copulation (EPC), Trivers (1972) predicted that males should seek extra matings as a means of increasing fitness, whereas females would not benefit from such behavior. Researchers investigating breeding settlement have considered the benefits of increased reproductive success through EPCs that males gain by attracting individuals to set- tle nearby (Morton et al 1990). It has become increasingly apparent, however, that females not only participate in extrapair matings, they actively seek EPCs on the territories of neighboring individuals (Smith 1988, Stutchbury and Neudorf 1997). This has led to a consideration of territory aggregation resulting from the benefits that females gain from engaging in EPC's (the "hidden-lek" hypothesis; Wagner 1993, 1997; Wagner et al 1996; Hoi and Hoi-Leitner 1997).

Female Black-capped Chickadees solicit EPCs on the territories of neighbors (Smith 1988), dlld extldpdil young (EPY) ocLu in approximately 30\% of nests (Otter et al. 1994, 1998). The genetic father of EPY in a given nest is a ncighbor that usually is socially dominant to the female's partner (Otter et al. 1994,1998). In a study of divorce in this species, females have been shown to abandon their current partner in favor of higher-ranking males if the opportunity arises (Otter and Ratcliffe 1996). Thus, females use EPC as a tactic to achieve genetic mate choice when social choice is constrained. To facilitate movement into the territories of extrapair males, females might choose to locate their nests near territory boundaries. Male chickadees differ in their dawn chorus performance based on social rank (Otter et al. 1997), and male singing behavior changes when females are experimentally removed from territories (Otter and Ratcliffe 1993). Thus, females could also benefit from locating their nests near territory boundaries through increased information on the status of neighboring males. Although locating centrally in the territory would allow a female to assess all of her neighbors, chickadees spend $\mathbf{8}$ to $\mathbf{1 0}$ months in flocks prior to nesting, providing ample opportunity to assess potential mating partners. Peripheral settlement could, therefore, give a female the opportunity to continue assessment of any preferred neighboring male.

The impetus for this study came from an observation in our study population in 1995. In that year, 11 of $\mathbf{2 6}$ females nested within approximately $15 \mathrm{~m}$ of their territory boundaries with neighbors (K. Otter unpubl. data). Nine of these 11 females were paired with males whose rank was lower than that of neighboring males. This pattern, together with the prolonged period of residency prior to nesting, is consistent 
with conspecific attraction based on mating tactics where females that are most likely to use alternative mating tactics nest near the boundaries of neighbors.

The purpose of this study was to test the four hypotheses outlined above in Black-capped Chickadees. If habitat characteristics determine nest location, then habitat at nest sites should differ from that at control sites. If prey abundance is the determining factor, then arthropod numbers should be higher at nest sites than at control sites. If previous experience determines nest location, and if the same birds occupy the same territories in multiple years, then the placement of nests should be consistent within individuals. Finally, if conspecific attraction based on mating tactics is a factor, then individuals that are likely to use EPCs or to divorce will nest the closest to territory boundaries, independent of habitat characteristics.

\section{Methods}

Study site and observations of dominance rank. - The study was conducted in 1996 and 1997 at Queen's University Biological Station, Ontario, Canada $\left(44^{\circ} 34^{\prime} \mathrm{N}, 76^{\circ} 19^{\prime} \mathrm{W}\right)$. The study site encompasses approximately 150 ha of eastern mixed-woods forest with maple (Acer spp.), ash (Fraxinus spp.), hickory (Carya spp.), and birch (Betula spp.) predominating. Several small fields and swamps are scattered throughout the study site.

Approximately 20 small flocks (four to six individuals each) of Black-capped Chickadees were permanent residents at the study site. Each winter feeding station attracted three to five flocks and served as a banding site in December and January and as a dominance platform from January to mid-March. In each year, approximately $95 \%$ of individuals in the population were captured using potter traps and marked with unique combinations of a numbered metal band and two or three plastic color bands. We assigned individuals to age class at the time of banding (serond year [SY] vs. after second year [ASY]) based on the shape and extent of white on the margins of the outer rectrices (Pyle et al. 1987).

We determined the social rank of individuals through observation of interactions at winter feeders based on the same behaviors used to distinguish dominants from subordinates in previous studies of this species (Ficken et al. 1990, Otter et al. 1994, Otter and Ratcliffe 1996). Linear dominance hierarchies were determined for each flock by tallying the outcomes of interactions between individuals. For any pair of individuals, the winner of the majority of interactions was considered to be dominant. Relative ranks were confirmed by comparing the outcomes of interactions with intermediate individuals that used the same feeder. We observed approximately 2,400 interactions at feeders in 1996 and 1997. Relative ranks for 230 within-flock dyads were based on a mean of $4.6 \pm$ SE of 0.3 interactions per dyad. In addition, while tracking flocks to determine home range each year, approximately $\mathbf{1 5}$ dominance interartinns hetween flnck mates were noted and included with data from feeder tallies. In all cases, these additional interactions agreed with observations at feeders.

Territory mapping and nest locations.-After the breakup of flocks in mid- to late April through the end of May, we tracked pairs on their territories every three to four days, noting the extent of movements, locations of boundary disputes, and locations of cavities. We used maps constructed from daily tracking to derive territory boundaries for pairs based on the methods of Bibby et al. (1992). Territory boundaries were fixed at the maximum extent of exclusively defended space. As the nesting season procccded, individuals concentrated their activities in a smaller area than the entire defended space (see Smith 1991), but presentations of taped vocalizations drew individuals to the previously defended boundaries. Only cavities containing nest cups were considered to be nests. Additional nest locations and territory boundaries mapped in 1995during other studies were used in the assessment of the effect of previous experience.

We obtained UTM coordinates for 1995,1996, and 1997 nest sites and 1996 and 1997 territory boundaries using a Trimble ProXL (real-time correction) global positioning system (GPS) unit. Real-time correction allows collection of positional data with an accuracy of less than 1 meler based un sintultaneous satellite tracking of both the GPS unit and a fixed navigation beacon. Data for nest sites were collected as point information, and boundary data were collected as lines.

Habitat characteristics. - We assessed habitat characteristics within $12.6-\mathrm{m}$ radius (0.05 ha) circular plots at nest sites and four control sites within each territory. Control sites were arranged with one central plot and three peripheral plots located $40 \mathrm{~m}$ from the center of the central plot at $0^{\prime \prime}, 120^{\circ}$, and $240^{\prime \prime}$. Control plots were chosen such that the peripheral plots would lie within the territory and none of the plots would overlap with the nest plot. Because control sites are defined by the absence of a nest and not by the presence of any particular attribute, we chose a four-plot design to account for the range of variation of habitat characteristics within each territory.

In 1996 only, we measured the following variables in each plot: ground-cover composition in $1-\mathrm{m}^{2}$ quadrats at the center of each plot and at $5 \mathrm{~m}$ from the center of the plot at each of the four cardinal points; and number, size $(<2 \mathrm{~cm}$ diameter and $\geq 2$ $\mathrm{cm}$ ) and species identity of shrub stems $>50 \mathrm{~cm}$ 
height in each of the four quadrats $5 \mathrm{~m}$ from the center of the plot. In both 1996 and 1997, we estimated overhead cover using the average of four spherical densiometer readings (one facing in each cardinal direction) at the center of each plot (Lemmon 1956);we estimated heights of the canopy, subcanopy, and tall shrub using a clinometer. Within the central 5-m radius of each plot, we counted the numbers nf live saplings $(<2.5 \mathrm{~cm} \mathrm{dbh})$ and poles $(2.5$ to $7.9 \mathrm{~cm} \mathrm{dbh})$ and identified each to species. Within the full $12.6-\mathrm{m}$ radius, we counted the number of stems of each tree species in each of tour size classes: 8 to $14.9 \mathrm{~cm}, 15$ to $22.9 \mathrm{~cm}, 23$ to $31.9 \mathrm{~cm}$, and $>32 \mathrm{~cm} \mathrm{dbh}$. We counted the numbers of standing dead stems $<8 \mathrm{~cm} \mathrm{dbh}$ and identified and measured dhh, height, and percent bark remaining for all snags $\geq 8 \mathrm{~cm}$ dbh.

We averaged the values from the four control plots in each territory to obtain a single value for each habitat characteristic. We compared the values for each characteristic between years using a two-tailed t-test to determine whether values could be pooled across years. For each variable, we compared vorinnccs bc tween nest and control plots using Bartlett's ANOVA to determine the appropriateness of using parametric versus nonparametric tests. If the variances did not differ between nests and controls, we compared means using two-tailed paired t-tests; if variances differed between nests and controls, we used twotailed paired Wilcoxon tests. For parametric tests, proportional data were arcsine transformed and counts were $\log (1+x)$ transformed (Sokal and Rohlf 1995).Because of the large number of tests, we used a sequential Bonferroni correction to reduce the possibility of type I error. This resulted in a critical value of $\alpha=0.00125$ for the variable with the lowest $P$-value and $\alpha-0.00128$ for that will the ntext luwest $P$ value.

We also compared nests and control sites using principal components analysis (PCA; lames and McCulloch 1990) based on a correlation matrix on the selected variables for all control sites. Using the eigenvectors generated by this analysis, we produced component scores for all sites and plotted the values for the first two principal components. We plotted 95\% density ellipses for control sites and nests, which provide a graphical representation of the used sites and their variance relative to the total variance of the available habitat (McCallum and Gelbach 1988, James and McCulloch 1990). Because of the large number of variables under consideration, we performed these analyses on subsets of the variables. In the first subset, we considered the physical characteristics of the trees and snags within each plot. These characteristics relate quantitatively to the available nesting and foraging substrates. We used transformed data in the analysis where appropriate.

The second subset of variables used in the PCA was tree species composition at each site. Tree species composition relates qualitatively to the suitabil- ity of nesting and foraging substrates. Because the data were originally collected as counts of stems in size categories for each species, we calculated an index of tree species composition (stem value) for plots using weighted sums of counts. For each species, saplings were given a weighting of 0.25 , poles 0.5 , trees 8 to $14.9 \mathrm{~cm}$ were weighted as 1,15 to $22.9 \mathrm{~cm}$ as $7,2.3$ tn $319 \mathrm{~cm}$ as 4 , and $>32 \mathrm{~cm}$ as 8 These weightings were chosen because they approximate the scaling of basal area for trees in each size category. We analyzed the resulting stem values for each plot using the method outlined above. We conducted all analyses using JMP and StatView SE + Graphics software for the Macintosh.

Prey abundance.-We compared the number of arthropods collected from branch samples in nest and control plots (the same plots used for measuring habitat characteristics) in each territory. We conducted arthropod sampling from 13 to 20 June in both years. We cut five 1-m long branches from the lower limbs of trees in each plot (average $5 \mathrm{~m}$ above ground, range 3 to $10 \mathrm{~m}$ ). This sampling height range is representative of the heights at which chickadees in our population glean arthropods while foraging (S. Ramsay pers. obs.). We caught each branch before it landed on the ground, placed it in a cloth bag, and then shook the bag vigorously to remove loose arthropods. Next, we inspected each branch and removed with forceps any spiders and insect larvae in cocoons or leaves rolled and bound with silk. All of the arthropods from a plot were stored in $70 \%$ ethanol in sample cups for later sorting and counting. This sampling protocol provided the best estimate of the abundance of sessile leaf-dwelling organisms such as spiders and larvae that make up the bulk of iterms provided to nestlings by adult chickadees (Woinarski and Cullen 1984, Majer and Recher 1988, Grundel 1990).

We sorted arthropods in each sample into the following groups: spiders, larvae (including coleopterans, hymenopterans, and lepidopterans), and "others." Within each group (spiders, larvae, and others), individuals were sorted into the following bodylength classes: $<2 \mathrm{~mm}, 2$ to $4.9 \mathrm{~mm}, 5$ to $9.9 \mathrm{~mm}$, and $>10 \mathrm{~mm}$. Sample counts were multiplied by overhead cover and canopy height to nhtain a plot estimate of arthropod abundance (Schroeder 1990).

As with habitat characteristics, we averaged counts across control plots within each territory and used paired t-tests if variances were equal and paired Wilcoxon tests if variances were unequal. Because the prey-abundance hypothesis predicts higher abundance at nest sites, we used one-tailed comparisons. In addition to the univariate comparisons, we analyzed all groups and size classes using PCA.

Previous-experience and conspecific-attraction hypotheses.-We extracted numerical values for positions and generated maps using AutoCad Map for Windows at the Queen's University Geographical Infor- 


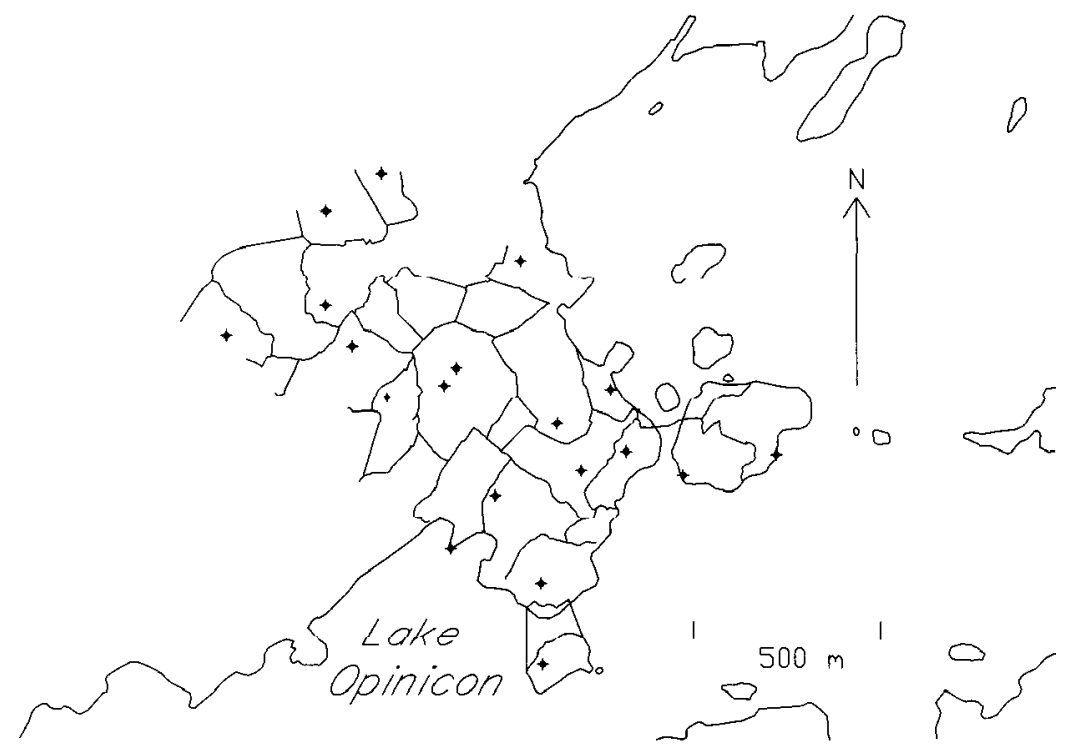

FIG. 1. Map of Queen's University Biological Station showing territory boundaries (solid lines) and nest sites (circled crosses) of Black-capped Chickadees in 1996.

mation Systems laboratory. Distances between nests across years, and between nests and boundaries within years, were extracted using the Pythagorean formula.

We considered a nest to be successful if one or more offspring survived to fledging (defining fledging as leaving the nest). These data were collected through nest monitoring for other studies and were hased on direct ohservations intn nests, observations of parental attendance at nests, or observations of adults traveling with fledged young.

\section{REsUlts}

Territory mapping. -We found 19 nests in 1996 and 26 nests in 1997. The positions of nests and boundaries for each year are illustrated in Figures 1 and 2. One territory in 1996 had two nest sites; the second was built by a replacement female after the original female was depredated on the territory. Because these nests were initiated by different females, we considered them to be independent measures of nest choice.

Habitat characteristics. - White birch (Betula papyrifera) was the most common species used for nesting (16 of 45 nests, 35.6\%), with sugar maple (Acersaccharum) next most common (5 of $45,11.1 \%)$ Nest trees averaged $8.7 \pm$ SE of 1.2 $\mathrm{m}$ tall and $20.5 \pm 2.1 \mathrm{~cm}$ in dbh; cavity entranc- es averaged $5.3 \pm 0.8 \mathrm{~m}$ above ground. Thirty nests $(667 \%)$ were in dead trees

Only 1 of the 27 habitat characteristics that we measured differed significantly between nest sites and controls (Table 1). Abundance of large trees $(\geq 32 \mathrm{~cm} \mathrm{dbh}$ ) was significantly higher at control sites than at nest sites in 1996 (paired $\mathrm{t}=3.13$, df $=18, P<0.01$ ) and 1997 (paired $t=\mathbf{2 . 2 2}$, df $=25, P<0.04$ ). The results were not significantly different between years $(\mathrm{t}=1.02$, df $=88, P>0.3)$, and pooling the results yielded a significant differenceoverall between nests and controls (paired $\mathrm{t}=3.76, \mathrm{df}=$ 44, $P=0.0005)$

Analysis of the physical characteristics of trees generated four principal components that explained $67.2 \%$ of the total variance (Table 2 ). PC1 explained $37.5 \%$ of the total variance and had strong positive contributions from all variables except those related to trees and snags $<8 \mathrm{~cm} \mathrm{dbh}$; the numbers of saplings and poles were weakly positive in their contribution to PC1, and the number of small snags made no contribution to PC1. Thus, PC1 was positively related to stand age and canopy closure. PC2 explained $12.2 \%$ of the variance and had high positive loadings for the number of small snags, number of poles, and number of saplings and moderate positive loadings for num- 


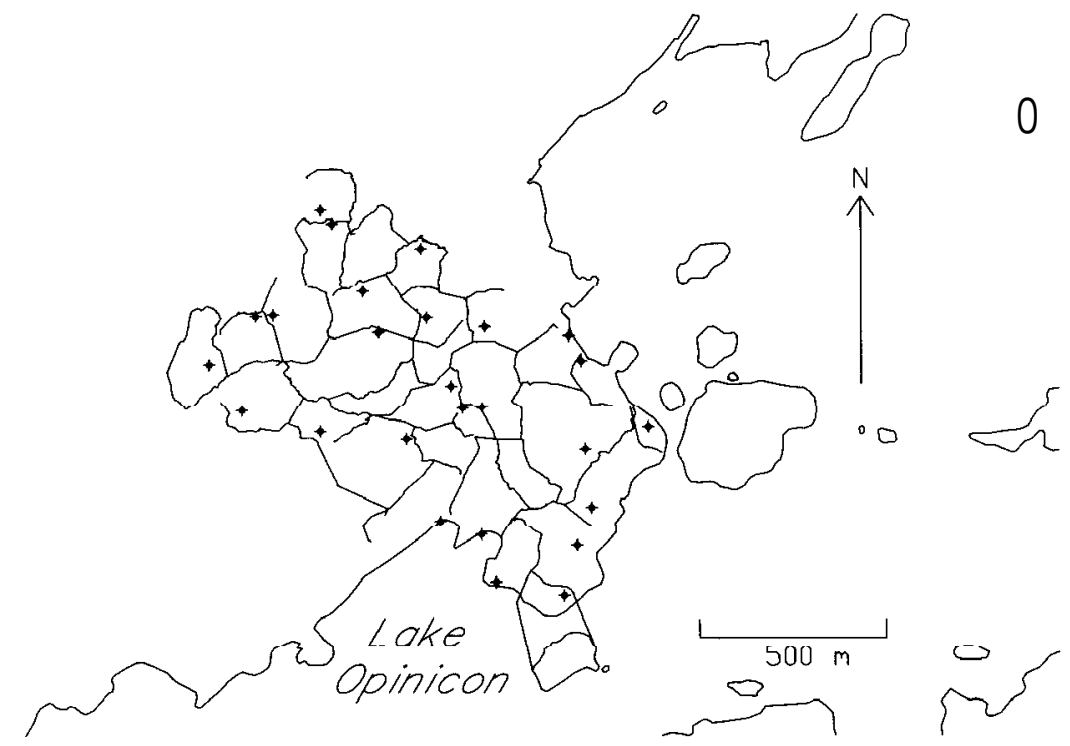

FIG. 2. Map of Queen's University Biological Station showing territory boundaries (solid lines) and nest sites (circled crosses) of Black-capped Chickadees in 1997.

ber of trees in the smallest size class and number of large snags. PC2 was negatively associated with the number of trees in the largest size class and canopy height. All other variables had weak loadings. Thus, this component appears to be related to the amount of infilling by young trees at a site. Concentration ellipses for control and nest sites revealed no difference in mean or variance for nest sites within the available habitat $(P>0.05$; Fig. 3A).

PCA generated seven factors that explained $57.5 \%$ of the variance in species composition across control sites (Table 3). PC1 explained $11.9 \%$ of the total variance and was characterized by high positive loadings for sugar maple, ironwoods (Ostrya virginiana and Carpinus caroliniana), basswood (Tilia americana), oaks (Quercus spp.), walnuts (Juglans spp.), and beech (Fagus grandifolia) and high negative loading for elms (Ulmus spp.) and large shrubby species such as alders (Alnus spp.), willows (Salix sppj. and staghorn sumac (Rhustyphina). Thus, PC1 appeared to separate wet sites from dry sites. PC2 explained $9.9 \%$ of the variance and was positively associated with birches and conifers and negatively associated with most of the hardwood species. This component seemed to separate hardwood from softwood stands. Because of their low eigenvalues, we must be cautious in our interpretation of the true mean- ing of these components. Plotting the PC scores for all sites revealed no difference in mean or variance for nest sites compared with the available habitat $(P>0.05$; Fig. $3 B)$.

Prey abundance. - Arthropod abundance did not differ between years ( $P>0.1$ for all cases), so we pooled the results for both years. Because variances were unequal for all but one case (others $>10 \mathrm{~mm}$ ), we used Wilcoxon tests for all comparisons. We excluded two territories from the analysis, one because a nest of spiderlings yielded numbers 100 times larger than those at all other plots for spiders $<2 \mathrm{~mm}$, and another because one branch contained an infestation of hemipteran larvae that yielded values 1,000 times larger than those at all other plots for "others" $<2 \mathrm{~mm}$. Arthropod abundances were not significantly different between nest and control plots for any group and size class ( $\mathrm{P}>0.1$ for all cases; Table 4) .

Principal component analysis of arthropod categories generated five factors that explained $56.8 \%$ of the total variance across control sites (Table 5). All size classes of all groups had positive loadings for PC1, indicating that this factor best explained variation based on total abundance. PC2 was positively related to spiders and other arthropods in the middle two size classes. Insect larvae in the two smallest size classes, spiders in the smallest and largest 
TABle 1. Comparison of habitat characteristics $(\bar{x} \pm \mathrm{SE})$ between nests and control plots. Control values are means of four control plots on each territory. Comparisons were tested using paired t-tests or Wilcoxon signed-rank tests (Wilcoxon tests corrected for ties). Sample sizes are 19 for 1996, 26 for 1997, and 45 for the pooled samples; P-values are two-tailed.

\begin{tabular}{|c|c|c|c|c|c|}
\hline Variable & Year & Nests & Controls & Test & $P$ \\
\hline \multicolumn{6}{|c|}{ Trees } \\
\hline Overhead cover (\%) & 1996 & $67.24 \pm 5.70$ & $73.85 \pm 3.48$ & $z=0.80$ & 0.421 \\
\hline & 1997 & $78.23 \pm 4.43$ & $81.30 \pm 3.31$ & $z=0.32$ & 0.751 \\
\hline Mean height $(\mathrm{m})$ & Pooled & $15.27 \pm 1.13$ & $17.83 \pm 0.83$ & $z=1.79$ & 0.074 \\
\hline No. saplings & Pooled & $21.91 \pm 3.67$ & $22.53 \pm 2.14$ & $z=0.77$ & 0.441 \\
\hline No. poles & Pooled & $9.18 \pm 1.01$ & $9.48 \pm 1.15$ & $t=1.12$ & 0.268 \\
\hline No. 8 to $15 \mathrm{~cm} \mathrm{dbh}$ & Pooled & $18.18 \pm 1.67$ & $17.46 \pm 1.29$ & $t=1.00$ & 0.323 \\
\hline No. 15 to $23 \mathrm{~cm} \mathrm{dbh}$ & Pooled & $7.87 \pm 0.90$ & $7.25 \pm 0.52$ & $z=0.04$ & 0.967 \\
\hline No. 23 to $32 \mathrm{~cm} \mathrm{dbh}$ & Pooled & $2.87 \pm 0.40$ & $3.48 \pm 0.32$ & $t=2.24$ & 0.030 \\
\hline No. $\geq 32 \mathrm{~cm} \mathrm{dbh}$ & Pooled & $1.31 \pm 0.24$ & $2.52 \pm 0.25$ & $t=3.76$ & $0.0005^{\mathrm{a}}$ \\
\hline No. species & Pooled & $7.44 \pm 0.42$ & $7.46 \pm 0.26$ & $z=0.13$ & 0.899 \\
\hline Total no. stems & Pooled & $61.16 \pm 4.48$ & $62.72 \pm 3.10$ & $z=0.03$ & 0.973 \\
\hline \multicolumn{6}{|c|}{ Snags } \\
\hline Mean dbh $(\mathrm{cm})$ & Pooled & $16.53 \pm \mathbf{1 . 3 7}$ & $14.30 \pm 1.25$ & $t=1.36$ & 0.180 \\
\hline Mean height (m) & 1996 & $6.77 \pm 0.88$ & $6.62 \pm 0.82$ & $\mathrm{t}=0.17$ & 0.870 \\
\hline & 1997 & $5.02 \pm 0.69$ & $5.12 \pm 0.69$ & $t=0.11$ & 0.910 \\
\hline Mean \% bark & Pooled & $80.95 \pm 3.05$ & $72.11 \pm 2.59$ & $z=3.15$ & 0.0016 \\
\hline No. $\geq 8 \mathrm{~cm} \mathrm{dbh}$ & Pooled & $4.44 \pm 0.52$ & $3.05 \pm 0.29$ & $z=1.93$ & 0.053 \\
\hline No. $<8 \mathrm{~cm} \mathrm{dbh}$ & Pooled & $10.09 \pm 2.18$ & $13.46 \pm 2.61$ & $\mathrm{t}=2.52$ & 0.015 \\
\hline Total no. snags & Pooled & $14.53 \pm 2.35$ & $16.51 \pm 2.57$ & $t=1.78$ & 0.080 \\
\hline \multicolumn{6}{|c|}{ Shrubs } \\
\hline No. $<2 \mathrm{~cm} \mathrm{dbh}$ & 1996 & $2.47 \pm 1.48$ & $2.14 \pm 0.60$ & $t=0.19$ & 0.849 \\
\hline No. $\geq 2 \mathrm{~cm} \mathrm{dbh}$ & 1996 & $0.05 \pm 0.05$ & $0.05 \pm 0.04$ & $t=0.00$ & 1.000 \\
\hline No. species & 1996 & $0.53 \pm 0.19$ & $0.46 \pm 0.10$ & $z=1.09$ & 0.769 \\
\hline \multicolumn{6}{|c|}{ Ground cover } \\
\hline Shrub (\%) & 1996 & $8.68 \pm 1.83$ & $11.13 \pm 1.35$ & $\mathrm{t}=0.30$ & 0.277 \\
\hline Forb $(\%)$ & 1996 & $7.23 \pm 2.58$ & $5.77 \pm 1.82$ & $t=0.008$ & 0.994 \\
\hline Grass (\%) & 1996 & $7.59 \pm 3.85$ & $8.35 \pm 2.91$ & $t=0.71$ & 0.489 \\
\hline Fern/muss (\%) & 1996 & $4.68 \pm 1.79$ & $3.52 \pm 0.75$ & $z-0.68$ & 0.494 \\
\hline Leaf litter (\%) & 1996 & $68.93 \pm 8.07$ & $79.28 \pm 4.05$ & $z=0.84$ & 0.398 \\
\hline Woody debris (\%) & 1996 & $3.63 \pm 0.63$ & $2.93 \pm 0.35$ & $z=0.966$ & 0.334 \\
\hline Bare rock or soil $(\%)$ & 1996 & $14.59 \pm 5.07$ & $7.95 \pm 2.00$ & $z=0.33$ & 0.744 \\
\hline
\end{tabular}

Significant with Bonferroni correction, $\alpha=0.00128$

size classes, and other arthropods in the largest size class were negatively related to PC2. The remaining categories made only weak contributions to PC2. As was the case with tree species composition, the low eigenvalues for PC1 and PC2 dictate that we be cautious in our interpretation of these components. Plotting the $\mathrm{PC}$ scores of all sites revealed no difference in the mean or variance of nest sites compared with the available habitat for either component ( $\mathrm{P}>0.05$; Fig. 3C).

Previous experience. - In examining distances between nests on the same territory in consecutive years, we excluded territories where boundaries did not overlap in the next year. We compared results for territories where the female was the same between years (i.e. experienced) with those where the female was new to the territory between years (i.e. naive), and they were not significantly different $(t=0.93$, $P=0.36$; Fig. 4A). Females that switched territories between years were classified as naive because they could not have based their choice of nest site on their own experience in the previous year. Among experienced females, interyear nest distances for previously successful nesters $(\bar{x}=131.7 \pm 22.8 \mathrm{~m}, n=6)$ were larger than those for previously unsuccessful nesters $(\mathrm{X}=99.9 \pm 39.5, n=2)$. Because only two individuals fell into the unsuccessful class, it is inappropriate to apply a statistical test to these results. It is interesting to note, however, that the mean was quite high for successful females. In the only case where an experienced female switched mates between years, the female had been successful the first year. 
TABLE 2. Eigenvectors from principal components analysis of physical features of trees and snags at control sites. Proportional data were arcsine transformed and counts were log transformed. Only principal components with eigenvalues greater than 1.0 are reported.

\begin{tabular}{lcccr}
\hline \hline & \multicolumn{4}{c}{ Principal component } \\
\cline { 2 - 5 } \multicolumn{1}{c}{ Variable } & $\mathbf{1}$ & 2 & \multicolumn{1}{c}{3} & \multicolumn{1}{c}{4} \\
\hline Overhead cover & 0.3227 & -0.0803 & 0.3260 & 0.2016 \\
Mean tree height & $\mathbf{0 . 3 2 2 6}$ & $\mathbf{- 0 . 2 5 8 2}$ & $\mathbf{0 . 2 0 5 5}$ & $\mathbf{0 . 1 1 1 8}$ \\
No. saplings & 0.0762 & 0.4817 & 0.0178 & -0.0614 \\
No. poles & 0.0888 & 0.3854 & 0.2828 & 0.5613 \\
No. trees 8 to 15 cm dbh & 0.3138 & 0.1312 & 0.1797 & -0.3483 \\
No. trees 15 to 23 cm & $\mathbf{0 . 3 1 5 9}$ & $\mathbf{0 . 0 6 5 2}$ & $\mathbf{0 . 2 2 1 8}$ & $\mathbf{- 0 . 3 1 2 2}$ \\
No. trees 23 to 32 cm & 0.3062 & -0.0944 & 0.1758 & 0.1051 \\
No. trees > 32 cm dbh & 0.2100 & -0.4270 & 0.1040 & 0.3753 \\
No. tree species & 0.3444 & 0.1107 & 0.0562 & -0.3307 \\
Mean snag dbh & $\mathbf{0 . 2 3 3 5}$ & $\mathbf{0 . 0 4 1 1}$ & -0.4966 & $\mathbf{0 . 2 2 2 7}$ \\
Mean snag height & 0.2523 & -0.0065 & -0.4797 & 0.1894 \\
Mean snag \% bark & 0.3161 & 0.0475 & -0.3074 & -0.0616 \\
No. snags $\geq 8$ cm dbh & 0.3238 & 0.1050 & -0.2625 & -0.0491 \\
No. snags < 8 cm dbh & -0.0001 & 0.5535 & 0.0684 & 0.2372 \\
Eigenvalue & 5.246 & 1.715 & 1.393 & 1.056 \\
Cumulative variance explained (\%) & 37.47 & 49.73 & 59.68 & 67.22 \\
\hline
\end{tabular}

Conspecific attraction.-We compared the nest-to-boundary distances for territories where the nearest male neighbor was higher in rank than the focal female's mate with those where the neighburing male was lower in rank than the focal female's mate. To control for variable territory sizes, we scaled distance measurcs to territory diameter and then transformed the resulting proportions for comparisons. In the few cases where nests were located adjacent to physical boundaries such as shorelines or fields, nest-boundary distance was measured to the nearest boundary defended against conspecifics. To avoid pseudoreplication, we randomly excluded data for one of the two years for females that were sampled in both years; this resulted in the exclusion of one female from 1996 and two from 1997 for which the neighbor's rank was known in both years. Because the mean nest-to-boundary distance was significantly higher in $1996(\bar{x}=0.67 \pm$ $0.04)$ than in $1997(\bar{x}=0.42 \pm 0.04)$ for all females $(\mathrm{t}=4.63 \mathrm{df}=43, \mathrm{P}<0.0001)$, we treated each year separately (rig. 4b). In 1996, females located their nests significantly closer to territory boundaries when neighbors were higher ranked than their social partner than when nearest neighbors were lower ranked $(t=1.85$, df $=16, \mathrm{P}=0.04$; Fig. 4B). In 1997, nest placement did not differ based on rank of the neighboring male $(\mathrm{t}=0.08$, $\mathrm{df}=15, P=0.94$; Fig. 4B).
We also considered whether nest-to-boundary proximity was related to female age, female rank, or male age. In cases where the nest owners were the same between years, we randomly excluded (by year) 5 nests where female age and rank were known and 11 nests where male age was known. In 1996, nest-to-boundary distance of ASY females $(\overline{\boldsymbol{x}}=\mathbf{0 . 6 8} \pm 0.08)$ and $S Y$ females $(\bar{x}=0.63 \pm 0.14)$ did not differ significantly $(t=0.28$, df $=11, P=0.78)$. In 1997 , however, ASY females nested significantly closer to boundaries than did SY females $(\bar{x}=$ $0.37 \pm 0.04$ vs. $\bar{x}=0.50 \pm 0.05$, respectively; $t$ $=2.17$, df $=21, \mathrm{P}=0.04)$. We found no difference in nesting pattern based on female social rank in 1996 (high rank, $\bar{x}=0.78 \pm 0.11$; low rank, $\bar{x}=0.68 \pm 0.11 ; t=0.66, \mathrm{df}=8, \mathrm{P}=0.52$ ) or 1997 (high rank, $\bar{x}=0.41 \pm 0.04$; low rank, $\bar{x}=0.34 \pm 0.04 ; t=1.18, \mathrm{df}=12, P=0.26$ ). Similarly, nest-to-boundary distance did not differ based on male age in 1996 (ASY, $\bar{x}=0.68$ \pm 0.08 ; SY, $\bar{x}=0.80 \pm 0.14 ; t=0.77, \mathrm{df}=11, P$ $=0.46$ ) or 1997 (ASY, $\bar{x}=0.44 \pm 0.04$; SY, $\bar{x}=$ $0.36 \pm 0.05 ; t=1.29, \mathrm{dt}=18, \mu=0.21)$.

\section{DISCUSSION}

Our results were consistent with the conspecific-attraction hypothesis for choice of nest location by females and failed to support the other three hypotheses that we considered. In the univariate analyses, the only habitat character- 

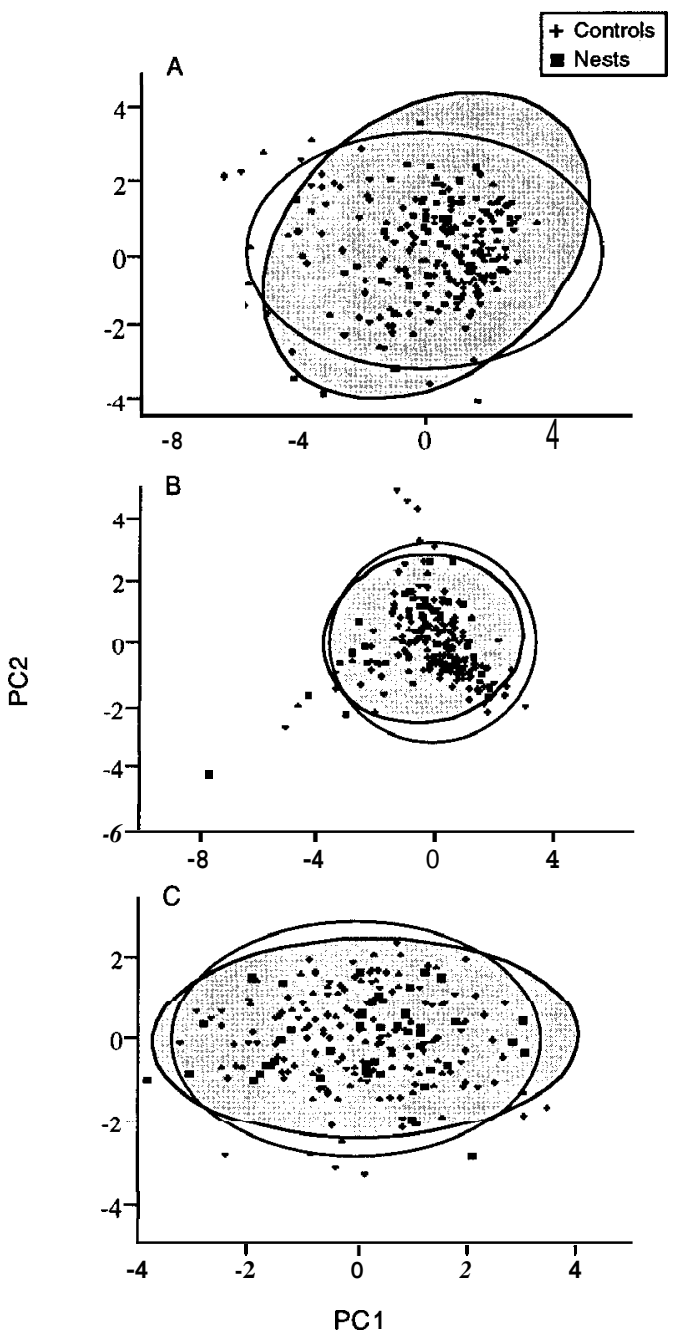

FIG. 3. Plots of PC1 vs. PC2 scores of nest plots and control plots generated from eigenvectors of PCAs of control plots for each subset of variables. Ellipses represent the $95 \%$ confidence space of nest sites (shaded)and control sites (open). (A) Physical features of trees and snags (see Table 2 for contribution of variables to each axis); (B) tree species composition (see Table $\mathbf{3}$ for contribution of variables to each axis); (C) arthropod abundance (see Table 5 for contribution of variables to each axis).

istic that was significantly different between nests and control sites in either year was density of large trees (i.e. fewer large trees at nest sites). Our four-plot control design allowed us to consider how variation in habitat characteristics in the available habitat compared with nest plots. First, we looked at the distribution of values across all control plots versus nest plots. The distribution of values for large trees suggests that this factor was not limiting within any given territory. Second, our multivariate analyses allowed us to consider the contribution of any individual variable to the overall variation in available habitat and to compare visually and statistically the pattern of used space with respect to unused space. The relatively low contribution of density of large trees in the PCA of habitat characteristics indicated that this variable was not a major determinant of nest-site location. Moreover, the density of large trees was lower at nests than at control sites, which is opposite to the results of Sedgwick and Knopf (1990) in Colorado. Overall, we detected no pattern of nest-site selectionbased on the variables that we measured.

Sedgwick and Knopf (1990)found that limbtree density (i.e. density of trees with $\geq 1 \mathrm{~m}$ of dead limbs larger than $10 \mathrm{~cm}$ in diameter) was the highest-loading variable in their discriminant function for chickadee nest sites. We found no difference in snag density (the comparable variable in this study) between nests and control sites. Sedgwick and Knopf (1990) also found a significant difference between nests and control sites for dead-limb length of the central tree within each plot. We did not measure this variable because the findings would not have been particularly meaningful in our study area. Although most of the chickadee nests in cottonwood habitat in Colorado were in live trees (Schroeder1990), most of the nests we found were in snags; therefore, any comparison of dead-limb length, by that fact alone, would have produced higher values for nest plots. Our results are consistent with those from Wisconsin and Minnesota in which Blackcapped Chickadee nests were not clearly related with any habitat variables (J. M. Hanowski pers. comm.).

The similarity in prey abundance between nests and control sites was not surprising and probably was directly related to the lack of variation in canopy density. The peak period when chickadees forage for arthropods, which is associated with provisioning nestlings, coincides with the peak in arthropod abundance. The availability of prey items is not likely to be a limiting factor for nestling provisioning at our study site.

We found no difference in nest locations on territories of experienced and naive individu- 
TABLE 3. Eigenvectors from principal components analysis of variation in tree species composition at control sites. Only principal components with eigenvalues greater than 1.0 are reported.

\begin{tabular}{|c|c|c|c|c|c|c|c|}
\hline \multirow[b]{2}{*}{ Variable } & \multicolumn{7}{|c|}{ Princiual comuonent } \\
\hline & 1 & 2 & 3 & 4 & 5 & 6 & 7 \\
\hline Sugar maple & 0.4081 & -0.2377 & 0.2361 & 0.0396 & -0.0294 & 0.0179 & 0.0684 \\
\hline Birches & -0.0416 & 0.4930 & 0.1269 & -0.0050 & -0.0303 & 0.2246 & 0.2138 \\
\hline Ironwoods & 0.3438 & 0.1552 & 0.2490 & 0.1897 & 0.0833 & 0.0327 & 0.2222 \\
\hline Basswood & 0.2872 & -0.2409 & 0.2032 & 0.0325 & -0.3456 & 0.1487 & 0.3646 \\
\hline White pine & -0.0476 & 0.2625 & -0.2999 & 0.3417 & -0.1568 & -0.2807 & -0.1356 \\
\hline Red oak & 0.2640 & 0.0003 & 0.0332 & 0.3734 & -0.0061 & -0.0915 & 0.3201 \\
\hline Elms & -0.4675 & -0.3516 & 0.1412 & 0.2413 & 0.0628 & 0.0314 & 0.0419 \\
\hline Other oaks & 0.1366 & -0.1161 & -0.4754 & 0.0567 & 0.2114 & -0.0435 & -0.1641 \\
\hline Ash/hickory & -0.0142 & -0.1127 & 0.0736 & -0.1051 & -0.3589 & 0.5346 & -0.4346 \\
\hline Poplars & 0.0351 & 0.0486 & 0.2496 & -0.1084 & 0.5511 & 0.1746 & -0.1902 \\
\hline Beech & 0.0591 & 0.0718 & -0.0828 & -0.0392 & 0.4573 & 0.3927 & 0.0497 \\
\hline Other maples & 0.0043 & 0.1332 & -0.1505 & 0.3564 & 0.2285 & 0.2634 & 0.3858 \\
\hline Conifers & -0.0828 & 0.5299 & 0.1923 & 0.0737 & -0.1643 & 0.0359 & -0.0428 \\
\hline Cherries & 0.0368 & 0.1197 & 0.3257 & 0.3965 & 0.0319 & -0.2021 & -0.4296 \\
\hline Walnuts & 0.1785 & -0.0178 & 0.4739 & -0.0542 & 0.2661 & -0.3521 & -0.0176 \\
\hline Small shrubs & -0.1129 & 0.0422 & -0.1117 & -0.5198 & 0.0354 & -0.3603 & 0.1996 \\
\hline Large shrubs & -0.5147 & -0.2778 & 0.1026 & 0.2378 & 0.0667 & -0.0229 & 0.1223 \\
\hline Eigenvalue & 2.022 & 1.675 & 1.410 & 1.256 & 1.213 & 1.154 & 1.046 \\
\hline $\begin{array}{l}\text { Cumulative variance explained } \\
(\%)\end{array}$ & 11.89 & 21.74 & 30.03 & 37.42 & 44.56 & 51.35 & 57.50 \\
\hline
\end{tabular}

als relative to the nest location in the previous year. It is interesting to note that none of the experienced females in two years nested closer than $60 \mathrm{~m}$ to their previous nest sites. Therefore, we can safely exclude the possibility that individual females choose similar nest locations between years, although the possibility exists that previous experience causes females to avoid previous nest locations independent of previous fledging success. Individuals have no difficulty reusing old nest cavities; however, they excavate regardless of whether a hole is new or reused (Smith1991, S. Ramsay personal obs.). In each year of the study we found four nests in old cavities.

To facilitate movement into the territories of extrapair males, females might choose to locate their nests near territory boundaries. The activ-

TABLE 4. Arthropod abundance by category and size for Black-capped Chickadee nests and control plots. Abunddnces were calculated based on numbers present on five 1-n lung branches cut from trees in eadh plot and scaled to canopy volume by multiplying by overhead cover and canopy height. Values are $\bar{x} \pm$ SE; Z-scores are from paired Wilcoxon tests and are corrected for ties; P-values are one-tailed; $n=45$ for all samples except spiders and others $<2 \mathrm{~mm}(n=44)$.

\begin{tabular}{|c|c|c|c|c|}
\hline Size (mm) & Nests & Controls & $Z$ & $P$ \\
\hline \multicolumn{5}{|c|}{ Spiders } \\
\hline$<2$ & $459.8 \div 190.1$ & $571.8+121.8$ & 1.45 & 0.93 \\
\hline 2 to 4.9 & $1,713.0 \pm 307.3$ & $2.038 .7+303.8$ & 1.28 & 0.90 \\
\hline 5 to 9.9 & $725.3+219.5$ & $548.8 \pm 100.2$ & 0.08 & 0.47 \\
\hline$\geq 10$ & $94.8 \pm 47.4$ & $132.1 \pm 39.0$ & 0.60 & 0.73 \\
\hline \multicolumn{5}{|c|}{ Larvae } \\
\hline$<2$ & $316.1 \pm 108.4$ & $427.0 \pm 187.0$ & 0.30 & 0.62 \\
\hline 2 to 4.9 & $1,359.1 \pm 268.5$ & $1,844.8 \pm 236.2$ & 2.30 & 0.99 \\
\hline 5 to 9.9 & $2,255.3 \pm 669.1$ & $2,036.2 \pm 213.0$ & 1.24 & 0.11 \\
\hline 210 & $6,364.9 \pm 1,259.4$ & $5,675.7 \pm 1,714.9$ & 0.85 & 0.20 \\
\hline \multicolumn{5}{|c|}{ Others } \\
\hline$<2$ & $3,028.5 \pm 588.9$ & $7,771.8 \pm 569.1$ & 2.04 & 0.98 \\
\hline 2 to 4.9 & $3,252.0 \pm 633.7$ & $4,793.6 \pm 700.2$ & 2.25 & 0.99 \\
\hline 5 to 9.9 & $1,252.4 \pm 352.6$ & $1,506.6 \pm 295.4$ & 1.17 & 0.88 \\
\hline 210 & $393.5 \pm 139.9$ & $342.0 \pm 76.5$ & 0.48 & 0.32 \\
\hline
\end{tabular}


TABLE 5. Eigenvectors from principal components analysis of variation in arthropod abundance at control sites. All counts were log transformed. Only principal components with eigenvalues greater than 1.0 are reported.

\begin{tabular}{|c|c|c|c|c|c|}
\hline \multirow[b]{2}{*}{ Variable } & \multicolumn{5}{|c|}{ Principal component } \\
\hline & 1 & 2 & 3 & 4 & 5 \\
\hline No. spiders $<2 \mathrm{~mm}$ & 0.2050 & -0.1381 & 0.5481 & -0.1615 & -0.0577 \\
\hline No. larvae $<2 \mathrm{~mm}$ & $0.234 \mathrm{I}$ & -0.3514 & -0.1966 & -0.4160 & -0.1834 \\
\hline No. others $<2 \mathrm{~mm}$ & 0.2680 & 0.0817 & 0.3717 & 0.1439 & -0.4613 \\
\hline No. spiders 2 to $5 \mathrm{~mm}$ & 0.2016 & 0.5507 & -0.1060 & -0.3261 & -0.1015 \\
\hline No. larvae 2 to $5 \mathrm{~mm}$ & 0.4481 & -0.1385 & -0.3036 & 0.2426 & 0.0346 \\
\hline No. others 2 to $5 \mathrm{~mm}$ & 0.3382 & 0.1904 & -0.2788 & -0.1439 & -0.3738 \\
\hline No. spiders 5 to $10 \mathrm{~mm}$ & 0.0349 & 0.4318 & 0.1060 & 0.1052 & 0.4835 \\
\hline No. larvae 5 to $10 \mathrm{~mm}$ & 0.4077 & -0.0192 & -0.0540 & 0.1452 & 0.4350 \\
\hline No. others 5 to $10 \mathrm{~mm}$ & 0.2839 & 0.2384 & 0.4296 & 0.2532 & -0.0968 \\
\hline No. spiders $>10 \mathrm{~mm}$ & 0.1191 & -0.4627 & 0.3108 & -0.1374 & 0.2038 \\
\hline No. larvae $>10 \mathrm{~mm}$ & 0.4439 & -0.0488 & -0.0662 & -0.2164 & 0.3131 \\
\hline No. others $>10 \mathrm{~mm}$ & 0.1178 & -0.1780 & -0.2019 & 0.6575 & -0.1647 \\
\hline Eigenvalue & 1917 & 1.364 & 1128 & 1.166 & 1.0 .50 \\
\hline Cumulative variance explained (\%) & 15.93 & 27.30 & 38.36 & 48.08 & 56.83 \\
\hline
\end{tabular}

ity patterns of females are centered on the nest during excavation and nest building, and females spend the night roosting in their nest cavities during the egg-laying period (Smith 1991). Locating nests near boundaries could help females to reduce time spent on forays for EPCs and to monitor more effectively the location and partnership status of neighboring males; this could be especially important if a neighbor became widowed. Males, by contrast, should prefer nest locations away from territory boundaries. Anecdotal evidence suggests that males whose partners choose to nest near territory boundaries face increased aggression from neighbors as they attempt to defend the space around the nest. Thus, males should be interested in choosing a site away from territory boundaries. In our study, females tended to nest near territory boundaries. In both years, the pattern of settlement for individuals nesting near higher-ranked males was consistent with our understanding of female mating tactics in chickadees. The pattern in 1997, however, where pairs also nested near the boundaries of lower-ranked individuals was curious.

Age-based conspecific attraction predicts that young individuals should nest near boundaries of older individuals because of an inherent inability to accurately assess available habitat (Stamps 1988). Muller et al. (1997) found that naive House Wrens (Troglodytes aedon) were most the likely to be attracted to conspecifics, whereas experienced individuals tended to settle farther from neighbors. Under this hypothesis, naive individuals might use the presence of conspecifics as a signal of the suitability of the nesting habitat. The only agebased difference we found was in 1997, when ASY females nested nearer to boundaries than did SY females. Thus, our data failed to support conspecific attraction based on inexperience due to age.

Conspecific attraction based on mating tactics (the "hidden-lek" hypothesis; Wagner 1993, 1997) predicts that all individuals will choose to settle near boundaries instead of distributing themselves throughout the available habitat. The hidden-lek hypothesis explains aggregation of males as a result of female mating tactics and assumes that males will aggregate to have a chance of benefitting from female behavior. This matches the pattern that we found in 1997 but not in 1996. In a species such as Black-capped Chickadee, we might predict a conflict of interest between the sexes. Individuals of both sexes will face increased intrasexual aggression by concentrating activity near a boundary; however, only high-ranking males, and females mated with low-ranking males, will experience the benefit of obtaining EPCs (Otter et al. 1994, 1998). Because females appear to predominate in choice of nest site in this species, we predicted the females that use EPCs would nest nearer to boundaries than those that do not. The 1997 result, while inconsistent with this prediction, requires an explanation for the choice of those females that placed their 
A

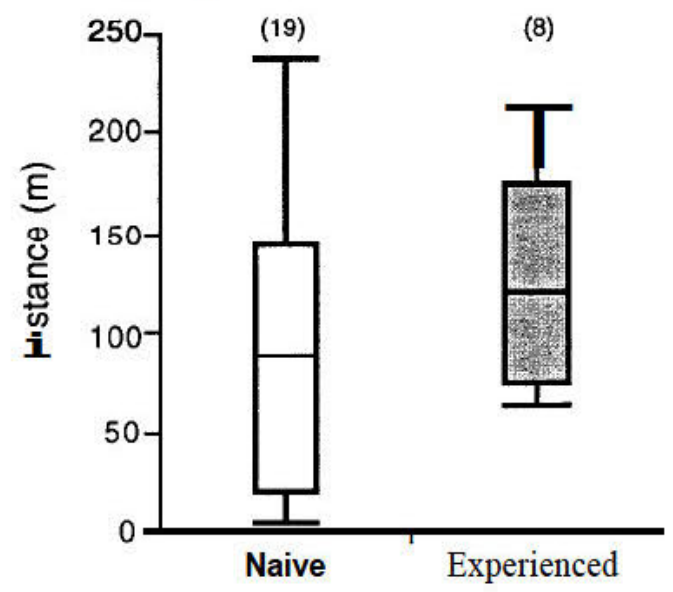

Female ID

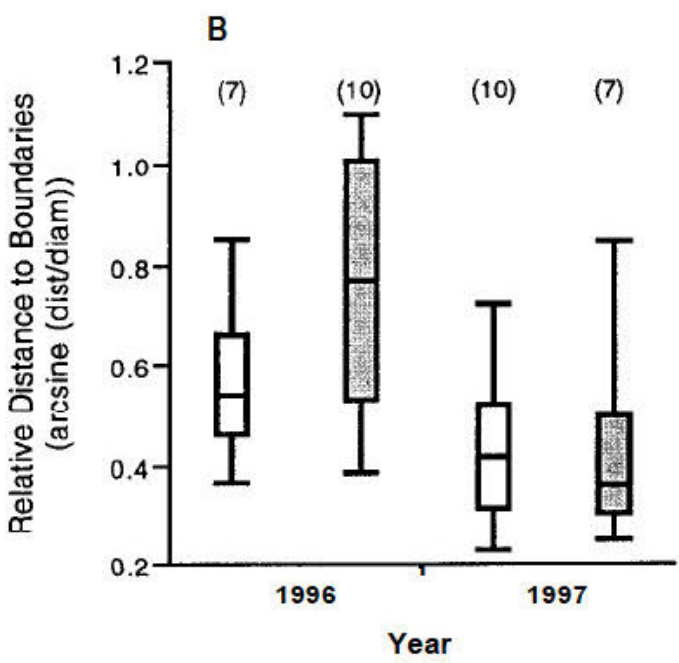

FIG. 4. (A) Interyear nest distances for naive (open box) vs. experienced (shaded box) female chickodccs. (B) Rclotive distance of nests to territory boundaries based on relative rank (open box $=$ higher rank, shaded box = lower rank) of nearest neighbor. In 1996, females nested closer to territory boundaries when nearest neighbors were higher-ranked than their mates vs. when they were lower-ranked. In 1997 , all females nested closer to territory boundaries than in 1996, regardless of the relative rank of neighbors. Sample sizes in parentheses.

nests near the boundaries of lower-ranking males.

Thus far, we have not considered why nests might be located near territory boundaries. One scenario would have females locating their nests near an established boundary, and a sec- ond scenario would have females choosing sites prior to their mates' defense of the surrounding space. Testing which of these scenarios is correct is difficult. To do so would require observing females in the act of initiating excavation and relating that to the time of boundary establishment. Nevertheless, either scenario suggests that a female's perception of space could be independent of her mate's. Under both scenarios, the female chooses a site and the male must deal with the consequences of her choice, either through increased aggression from a neighbor at a previously established boundary, or through the need to expand his defended space to include the nest site.

Our study is the first we know of to examine nesting patterns related to female choice of social and genetic partners in a socially monogamous, noncolonial species. We are conducting additional work that examines genetic paternity of offspring relative to nest placement. Studies of nest placement in other species should also pay attention to the attractiveness of neighboring males as social and extrapair partners.

\section{ACKNOWLEDGMENTS}

We thank C. Barber, T. Crowley, S. Tarof, N. Vreeswyk, B. J. Stutchbury, D. A. McCallum, and an anonymous reviewer for helpful comments on an earlier draft of the manuscript, and C. McDonald, C. James, A Nirwal, $W$ Mrl eish, and $T$ Talvila fnr field assistance. Logistical support was provided by the Queen's University Biological Station. The Curtis, Weatherhead-Metz, Monaghan, Warren, and Lundell families permitted access to their properties. Peg Hauschildt at Queen's GIS Lab provided a crash course in AutoCAD. Funding for the study was provided by donations from E. \& I. Ramsay and PPG Canada Inc.; a Society of Canadian Ornithologists Taverner Award, Chapman Memorial Award, American Ornithologists' Union Bleitz Award, and Ontario Graduate Scholarship to SMR; an Animal Behavior Award, John K. Cooper Award, Sigma Xi Grantin-aid of Research, Society of Canadian Ornithologist's Tavcrncr Award, and Ontario Craduatc Scholarship to $\mathrm{KO}$; and an NSERC operating grant to LMR.

\section{LITERATURE CITED}

AlbaNo, D. J. 1992. Nesting mortality of Carolina Chickadees breeding in natural cavities. Condor 94:371-382.

BELETSKY, L. D., AND G. H. ORIANS. 1991. Effects of 
breeding experience and familiarity on site fidelity in female Red-winged Blackbirds. Ecology $72: 787-796$.

Bibby, C. J., N. D. Burgess, And D. A. Hill. 1992.Bird census techniques. Academic Press, London.

BIRKHEAD, T. R. 1978. Behavioural adaptations to high density nesting in the Common Guillemot (Uria aalge). Animal Behaviour 26:321-331.

Christman, B. J., And A. A. Dhondt. 1997.Nest predation in Black-capped Chickadees: How safe are cavity nests? Auk 114:769-773.

DANCHIN, E., AND R. H. WAGNER. 1997. The evolution of coloniality: The emergence of new perspectives. Trends in Ecology and Evolution 12: 342-347.

Ficken, M. S., C. M. Weise, and J. W. Popp. 1990. Dominance rank and resource access in winter flocks of Black-capped Chickadees. Wilson Bulletin 102:623-633.

GRUNDEL, R. 1990. The role of dietary diversity, prey capture sequence and individuality in prey selection hy parent Mountain Chickadees (Parus gambeli). Journal of Animal Ecology 59:959-976.

HoI, H., AND M. HoI-LeITNER. 1997. An alternative route to coloniality in the Bearded Tit: Females pursue extra-pair fertilizations. Behavioral Ecology 8:113-119

HoRN, H. S. 1968. The adaptive significance of colonial nesting in Brewer's Blackbird (Euphagus cyanocephalus). Ecology 49:682-694.

Houtman, A. M. 1992. Female Zebra Finches choose extra-pair copulations with genetically attractive males. Proceedings of the Royal Society of London Series B 249:3-6.

JAMES, F. C., AND C. E. MCCulloCH. 1990. Multivariate analysis in ecology and systematics: Panacea or Pandora's box? Annual Review of Ecology and Systematics 21:129-166.

Kempenaers, B., G. R. Verheyen, M. Van Den Broeck, T. Burke, C. VAN Broeckhoven, AND A. A. DhOndT. 1992.Extra-pair paternity results from female preference for high-quality males in the Blue Tit. Nalure 357:494-496.

LACK, P. 1948. Notes on the ecology of the Robin. Ibis 90:252-279.

LEMMON, P. E. 1956. A spherical densiometer for estimating forest overstory density. Forestry Science 2:314-320.

LIFJELD, J. T., AND R. J. Robertson. 1992.Female control of extra-pair fertilization in Tree Swallows. Behavioral Ecology and Sociobiology 31:89-96.

Majer, J. D., AND H. F. Recher. 1988. Invertebrate communities on Western Australian eucalypts: A comparison of branch clipping and chemical knockdown procedures. Australian Journal of Ecology 13:269-278.

McCallum, D. A., and F. R. Gelbach. 1988. Nest site preferences of Flammulated Owls in western New Mexico. Condor 90:653-661.
Morton, E. S., L. Forman, And M. Braun. 1990.Extra-pair fertilizations and the evolution of colonial breeding in Purple Martins. Auk 107:275283.

Muller, K. L., J. A. Stamps, V. V. Krishnan, and N. H. WILliTs. 1997. The effects of conspecific attraction and habitat quality on habitat selection in territorial birds (Troglodytes aedon). American Naturalist 150:650-661.

Neudorf, D. L., B. J. M. StutchbuRy, AND W. H. PiPER. 1997. Covert extra-territorial behaviour of female Hooded Warblers. Behavioral Ecology 8: 595-600.

Odum, E. P. 1941. Annual cycle of the Black-capped Chickadee. 2. Auk 58:518-534.

Orians, G. H., AND N. E. Pearson. 1979. On the theory of central place foraging. Pages $155-177$ in Analysis of ecological systems (D. J. Horn, G. R. Stairs, and R. D. Mitchell, bds.). Ohı State University Press, Columbus.

Otter, K., B. Chruszcz, And L. Ratcliffe. 1997. Honest advertisement and singing during the dawn chorus of Black-capped Chickadees, Parus atricupillus. Behavioral Ecology 8:167-172.

OTTER, K., AND L. RATCLIFFE. 1993. Changes in singing behaviour of male Black-capped Chickadees (Parus atricupillus) following mate removal. Behavioral Ecology and Sociobiology 33:409-414.

Otter, K., AND L. Ratcliffe. 1996. Female initiated divorce in a monogamous songbird: Abandoning mates for males of higher quality. Proceedings of the Royal Society of London Series B 263: 351-354.

OtTeR, K., L. RAtClifFe, AND P. T. BoAG. 1994.Extrapair paternity in the Black-capped Chickadee. Condor 96:218-222.

Otter, K., L. Ratcliffe, D. Michaud, and P. T. BoAG. 1998. Do female Black-capped Chickadees prefer high-ranking males as extra-pair partners? Behavioral Ecology and Sociobiology 43:25-36.

Pyle, P., S. N. G. Howell, R. P. Yunick, AND D. F. DeSAnte. 1987. Identification guide to North American passerines. Slate Creek Press, Bolinas, California.

SCHROEDER, R. L. 1990. Tests of a habitat suitability model for Black-capped Chickadees. United States Fish and Wildlife Service Biological Report No. 90(10).

Sediwlck, J. A., anu F. L. Knulr. 1990. Habitat relationships and nest site characteristics of cavity-nesting birds in cottonwood floodplains. Journal of Wildlife Management 54:112-124.

SMith, S. M. 1974.Nest site selection in Black-capped Chickadees. Condor 76:478-479.

SмiтH, S. M. 1976. Ecological aspects of dominance hierarchies in Black-capped Chickadees. Auk 93: 95-107.

SMiтh, S. M. 1988. Extra-pair copulations in Black- 
capped Chickadees: The role of the female. Behaviour 107:15-23.

SMith, S. M. 1991. The Black-capped Chickadee: Behavioral ecology and natural history. Comstock Publishing, Ithaca, New York.

SOKAL, R. R., AND F. J. RoHLF. 1995. Biometry, 3rd ed. W. H. Freeman, New York.

STAMPS, J. A. 1988. Conspecific attraction and aggregation in territorial species. American Naturalist 131:329-347.

Stutchbury, B. J., AND D. L. NeUdorf. 1997. Female control, breeding synchrony, and the evolution of extra-pair mating tactics. Pages 103-121 in Avian reproductive tactics: Female and male perspectives (P. G. Parker and N. T. Burley, Eds.). Ornithological Monographs No. 49.

TRIVERS, R. L. 1972. Parental investment and sexual selection. Pages 136-179 in Sexual selection and the descent of man 1871-1971 (B. Campbell,Ed.) Aldine Publishing, Chicago.
WAGNER, R. H. 1993. The pursuit of extra-pair copulations by female birds: A new hypothesis of colony formation. Journal of Theoretical Biology 163:333-346.

WAGNER, R. H. 1997. Hidden leks: Sexual selection and the clumping of avian territories. Pages 123145 in Avian reproductive tactics: Female and male perspectives (P. G. Parker and N. T. Burley, Eds.). Ornithological Monographs No. 49.

Wagner, R. H., M. D. SChug, and E. S. Morton. 1996. Condition-dependent control of paternity by female Purple Martins: Intplicaliuns for coloniality. Behavioral Ecology and Sociobiology 38:379-389.

WoinARSKi, I. C. Z., AND I. M. Cullen, 1984. Distribution of invertebrates on foliage in forests of south-eastern Australia. Australian Journal of Ecology 9:207-232.

Associate Editor: L. J. Petit 